\title{
ANTHOLOGY \\ A Test for Threshold Effects in Bank Entry
}

\author{
MICHAEL L. MARLOW \\ George Washington University
}

While there exists an empirical literature on the market structure-performance relationship in banking, the possibility of threshold effects in bank entry has not been addressed. Two possible concerns relating to threshold effects are presented. One is whether or not increased market entry exerts differential effects on performance as related to current levels of competition. For example, does an $X$ percent increase in entry exert a larger effect on performance in markets with a relatively few number of firms per capita versus markets with a larger number? The second concern is whether or not it makes a difference on performance if entry is de novo or by branches. For example, do de novo or branch entry exhibit different thresholds?

Regression analysis relates market performance and possible threshold effects. Performance is gauged by the effective interest rate charged on conventional mortgages by banks, savings and loans, and mutual banks. A crosssectional sample of 39 cities is chosen so that they are located in states without unit banking laws. This choice is made for two reasons. One is to allow for both de novo and branch entry. The other is to minimize the impact of entry on performance by bank holding companies (BHC's). It is widely accepted that the growth of BHC's has been greatest in unit banking states.
The basic equation uses the interest rate by city in 1975 as the dependent variable. The independent variables are population growth, term-to-maturity, loan-to-value, percentage growth in entry, and a dummy variable to measure for threshold effects. The dummy variable is set up so as to separate out cases of banks per capita above certain hypothesized threshold values. Threshold points are chosen by first measuring the average number of banks per capita. Subtracting one, one and one-half, two and two and one-half standard deviations of this variable from this average number of banks per capita variable forms four possible threshold points. Also, by adding these multiples of the standard deviation to the average banks per capita variable forms four possible saturation points.

The following results are obtained. The nonentry variables are found to exert the expected and significant effects on performance. While both de novo and branch entry variables exert significant and competitive effects on performance, the threshold and saturation dummies do not exert significant impacts. That is, both types of entry are found to exert positive effects on performance which are undifferentiated by present levels of competition. The implication is that both types of entry offer means of improving performance in these 39 markets. 